\title{
sciendo
}

\section{A modelling proposal for the public interest under the European resolution framework}

\author{
Gabriel Razvan MITRACHE \\ Bucharest University of Economic Studies, Bucharest, Romania \\ gabriel.mitrache@gmail.com
}

Disclaimer. The opinions and assessments herein presented pertain to the author and should not be related to the views of his employer. The author's employer is not liable in any way for the present paper and did not contribute to it in any way.

\begin{abstract}
The post 2008 financial crisis reform package includes the bank resolution framework. Among other measures, it foresees that failing banks should be left under insolvency proceedings, unless they meet their salvage is in the public interest. The Bank Recovery and Resolution Directive defines the public interest, providing guidance that resolution authorities need to take into account when deciding between resolution (continuation of the bank's activity) or liquidation when a bank fails. While the guidance stems for a legal act, the concept can be mathematically modelled together with the underlying decision making process. To date, only parts of the resolution public interest or the concept of financial crisis have been modelled. The public interest assessment and underlying decision process, to the knowledge of the author, have not been mathematically modelled. This paper proposes a mathematical model for the public interest assessment as provided under the European resolution framework. While this seems to be the first such effort, it should be seen as a basis for further critical thinking that should allow more advancements that would ultimately facilitate the assessment and to provide insights for its intended users. The model can be easily implemented by practitioners by selecting or adding more relevant variables and most importantly by following their own calibration. The model is designed in a way to enable integration in an artificial intelligence deployment on data that authorities collect on the economies.
\end{abstract}

Keywords: bank resolution, regulatory, public interest, banking, central banking, model, BRRD.

\section{Introduction}

The Bank Recovery and Resolution Directive (BRRD) introduced in 2014 the requirement that in case of a bank failure, authorities can intervene to allow continuation of its functioning only if it meets the public interest assessment (PIA), under certain conditions. Otherwise, the failing banks should undergo liquidation in insolvency procedures.

The resolution framework provides objectives for a resolution action and sets the threshold that resolution should be pursued only if insolvency cannot meet to the same extent the resolution objectives.

Since the decision of a resolution authority can be only binary - action is required in the public interest or not - a modelling of the public interest concept and underlying decision process is feasible. Ultimately, the decision on PIA is an assessment function that can take only two values: true or false.

We propose a systematisation of the assessment of the public interest for the European resolution framework. Such a model could be used as a basis for more concrete parametrisation and customisation for practical utilisation. In any case, the model - a simplified representation of the complex reality - should facilitate the understanding of the stages and of the process. 


\section{Literature review}

While public interest is a matter of research in many scientific fields, with discussions on various levels, no modelling could be retrieved to the public interest required under the resolution framework. In general, research papers regarding public interest indicate the underlying complexity for any public interest related discussion. "The ontological debate on the public interest concludes that the problem defeating any substantive public interest application is complexity, leaving a dialogic public interest as a default legitimator of public planning." (Alexander, 2002)

Some research papers model various parts of the public interest under the resolution framework. Two papers propose a model in a game theory approach for the decision that authorities need to make when faced with a failing institution. These models show that the larger and more complex the institution, governments and authorities will intervene to save a failing institution. The papers could be read as implying that since there is no adequate tool to determine a threshold to consider when intervention is required (as opposed to leaving the failed bank exit the market through insolvency) and given there are no adequate measures to determine the negative externalities on the economy, it is more likely that there will be an intervention to save the failing bank. In other words, not having a tool to model the public interest for financial purposes triggers a likely positive assessment of the public interest (Mitrache, A game of bank resolution, 2018). "The central role of the technology constraint in this model highlights a crucial determinant of failed bank resolution policy that has been overlooked in the theory literature to date; without improved resolution technologies, future bank bailouts are inevitable. The effects of political pressure in this model remind us that regulatory reform is only as good as the regulators that implement the reform." (DeYoung, Kowalik, \& Reidhill, 2013)

A different paper proposes a modelling of what is part of the European framework public interest under resolution. Indeed, the legal framework indicates the public interest as having five components (which we will discuss in more detail in this paper), one of them relating to critical functions. Mitrache (2018) proposes a model for quantifying and assessing critical functions in the European resolution framework, as part of the public interest concept.

\section{What is a model?}

"Scientific modelling is the generation of a physical, conceptual, or mathematical representation of a real phenomenon that is difficult to observe directly. Scientific models are used to explain and predict the behaviour of real objects or systems. [...] In fact, in the attempt to fully understand an object or system, multiple models, each representing a part of the object or system, are needed." (Rogers, 2011)

In this paper, we will construct a mathematical model of an economic concept, the public interest assessment under the resolution framework. Therefore, definitions of mathematical and economic models will be first sought out.

"Mathematical modeling is the art of translating problems from an application area into tractable mathematical formulations whose theoretical and numerical analysis provides insight, answers, and guidance useful for the originating application." (Neumaier, 2004)

"An economic model is a simplified description of reality, designed to yield hypotheses about economic behavior that can be tested. An important feature of an economic model is that it is necessarily subjective in design because there are no objective measures of economic outcomes. [...] Economic models generally consist of a set of mathematical equations that describe a theory of economic behavior. The aim of model builders is to include enough equations to provide useful 
clues about how rational agents behave or how an economy works. The structure of the equations reflects the model builder's attempt to simplify reality." (Ouliaris, 2011)

\section{The public interest under the European resolution framework?}

Directive 2014/59/EU, known as the Bank Recovery and Resolution Directive (BRRD) (European Parliament and Council, 2014) provides a framework of "comprehensive and effective arrangements to deal with failing banks at national level and cooperation arrangements to tackle cross-border banking failures. [...] A bank resolution occurs when authorities determine that a failing bank cannot go through normal insolvency proceedings without harming public interest and causing financial instability. To manage the bank's failure in an orderly manner, authorities use resolution tools that ensure continuity of the bank's critical functions, maintain financial stability, and restore the viability of parts or all of the bank" (European Commission, 2014).

Article 32(5) of the BRRD provides that "a resolution action shall be treated as in the public interest if it is necessary for the achievement of and is proportionate to one or more of the resolution objectives referred to in Article 31 [BRRD] and winding up of the institution under normal insolvency proceedings would not meet those resolution objectives to the same extent."

Article 31(2) of the BRRD provides the five objective of a resolution action: "(a) to ensure the continuity of critical functions; (b) to avoid a significant adverse effect on the financial system, in particular by preventing contagion, including to market infrastructures, and by maintaining market discipline; (c) to protect public funds by minimising reliance on extraordinary public financial support; (d) to protect depositors covered by Directive 2014/49/EU and investors covered by Directive 97/9/EC; (e) to protect client funds and client assets. When pursuing the above objectives, the resolution authority shall seek to minimise the cost of resolution and avoid destruction of value unless necessary to achieve the resolution objectives."

\section{A model proposal for the Public Interest in the EU Resolution framework}

Statistician George Box euphemistically described the shortcomings and at the same time benefits of mathematical models: "Now it would be very remarkable if any system existing in the real world could be exactly represented by any simple model. [...] For such a model there is no need to ask the question "Is the model true?". If "truth" is to be the "whole truth" the answer must be "No". The only question of interest is "Is the model illuminating and useful?"” (Box, 1979). The above excerpts are included in a paper under the very insightful section labelled "All models are wrong but some are useful".

The public interest assessment, in case of a bank failure, can only conduct to a binary outcome: public interest is met or it is not met. Resolution authorities need to act swiftly and cannot afford to lose time in philosophical debates of the extent to which the public interest is met or not. Fortunately, binary decisions are some of the best candidates for mathematical modelling.

The BRRD requires the assessment of the extent of reaching the 5 objectives in resolution compared to insolvency proceedings. This requirement can graphically be represented as seen in Figure 1. In this figure, the five resolution objectives are plotted with an imaginary outcome, on a scale from 0 to 100 , on a fictitious example. 


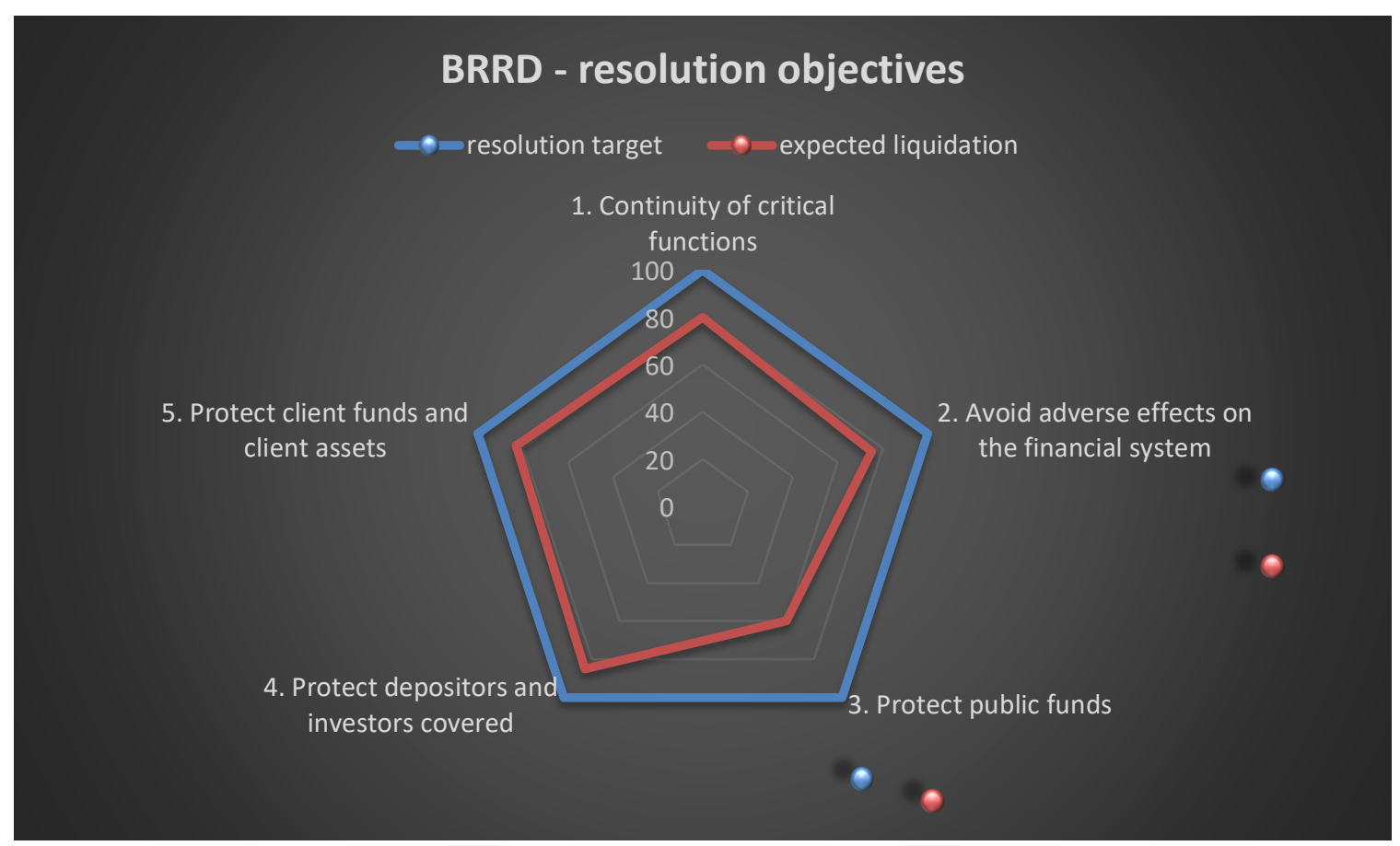

Figure 1. Representation of resolution objectives as defined in article 31 of the BRRD. To choose resolution action, meeting the resolution objectives through resolution should be superior to liquidation expected outcome. Chart values are for a fictitious case, for graphical purposes only.

Source: Author own creation.

A more detailed explanation for Figure 1 representation is need, as we have already dived into PIA modelling. We assumed for each of the five objective a scale from 0 to 100 . As the legal framework requires to determine the extent to which each objective is met in resolution versus liquidation, we propose to measure the extent of meeting the objectives independently on this custom created scale. The point on each axis represents the measure the objective is reached where 0 means nothing of that objective is reached and 100 means the objective is reached in its entirety. While the scores in Figure 1 is for illustrative purposes only, in an actual case, the resolution authority will have to make the assessment based on a (ideally) predetermined way of measuring how the criteria are met to reach each point on the 100 scale.

In theory, resolution action should achieve entirely its objectives, therefore the blue representing resolution action outcome is perfect - a pentagon in our illustration. Further, resolution action should better achieve the objectives compared to liquidation, therefore, the orange line representing a theoretical insolvency outcome that does not reach $100 \%$. The rate at which the insolvency achieves the objectives in this figure is arbitrary and is only for illustrative purposes.

$$
P I A=\sum_{n=1}^{5} \quad\left(O R_{n}-O I_{n}\right)
$$

In this incipient model, the Public Interest Assessment (PIA) is positive if the result is a positive number and is not met in case of a negative number. The equation simply indicates that summing the differences between the levels of how each of the five objectives is met in resolution $(\mathrm{OR})$ versus how the same objective is met in insolvency (OI) will answer to the legal requirement. 
On the proposed scale of 100 points, the PIA outcome can vary between a minimum of -500 (where resolution action does not provide any result but insolvency would meet perfectly all of the objectives) to +500 (where resolution would perfectly meet all the five objectives while insolvency will not meet at all any of the objectives). Resolution action should therefore be considered for any strict positive value on this scale.

To go a level deeper in the model, we could envisage that the assessment of reaching each of the objectives shall be made by a combination of quantitative and qualitative factors $\left(\mathrm{L}\left\{\mathrm{OX}_{\mathrm{n}}\right\}-\right.$ Level of meeting objectives in resolution and insolvency, respectively).

$\mathrm{L}\left\{\mathrm{OR}_{\mathrm{n}}\right\}=\left(\mathrm{QT}_{\mathrm{n}}^{\mathrm{r}}, \mathrm{QL}_{\mathrm{n}}^{\mathrm{r}}\right)$

$\mathrm{L}\left\{\mathrm{OI}_{\mathrm{n}}\right\}=\left(\mathrm{QT}^{\mathrm{i}}, \mathrm{QL}_{\mathrm{n}}^{\mathrm{i}}\right)$

QT and QL are respectively the quantitative factors and qualitative factors taken into account for the resolution ( $\mathrm{r}$ or $\mathrm{i}$ superscript) for each of the 5 objectives ( $\mathrm{n}$ subscript).

At this stage, combining various quantitative and qualitative factors and scoring them on a 100 points scale could prove burdening. In practice, determining the actual level on which an objective is met on a certain scale could be a challenging task. We therefore introduce a new phase in the assessment that should eliminate this hurdle: the expert judgement. The expert judgement component, deployed on top of the quantitative and qualitative factors will indicate if the objective is met or not. If, for certain reasons, a certain scale would be retained for the quantitative or qualitative factors, applying the expert judgement would offer a high discriminatory power: the objective is met or not instead of transitory, intermediate continuum, in between meeting or not the objective.

$\mathrm{L}\left\{\mathrm{OR}_{\mathrm{n}}\right\}=\mathrm{EJ}\left(\mathrm{QT}^{\mathrm{r}}{ }_{\mathrm{n}}, \mathrm{QL}^{\mathrm{r}}{ }_{\mathrm{n}}\right)$

$\mathrm{L}\left\{\mathrm{OI}_{\mathrm{n}}\right\}=\mathrm{EJ}\left(\mathrm{QT}_{\mathrm{n}}^{\mathrm{i}}, \mathrm{QL}_{\mathrm{n}}^{\mathrm{i}}\right)$

In this assessment, where "EJ" stands for the expert judgement function, the level of attaining each of the objectives can be 1 or 0 , i.e., the objective is met or not. Therefore, the overall PIA assessment can take values from -5 to +5 , where all strict positive values indicate that resolution action should be taken.

For demonstrating how the model would be employed, let us consider its usage for one objective. Let us suppose we want to assess how resolution action would meet the objective of ensuring the continuity of critical functions.

Figure 2 displays a graphical representation of the quantitative and qualitative assessment of the objective of ensuring the continuity of critical functions. The model is run for all banks simulated in a banking system (series from 1 to 10). Each layer on the graph takes a value on a continuum between 1 and 100. If for the lower and higher values it can be assumed that the objective is met or not, for the middle layers the conclusion could be more problematic: the use of the quantitative and qualitative assessment could have low discriminatory power in certain circumstances. As indicated above, the higher discriminatory power could be achieved through the use of expert judgement. In this case, the model relies on a function of the form $\mathrm{CF}(\mathrm{X})=\mathrm{EJ}(\mathrm{Qual}(\mathrm{x} 1)(\mathrm{Quant}(\mathrm{x} 2))$, where $\mathrm{X}$ is the institution assessed, and $\mathrm{x} 1$ and $\mathrm{x} 2$ are vectors containing values for the institution $\mathrm{X}$ in the criteria used for each of the qualitative and quantitative functions, respectively.

DOI: 10.2478/picbe-2021-0112,pp. 1208-1218, ISSN 2558-9652 |

Proceedings of the $15^{\text {th }}$ International Conference on Business Excellence 2021 


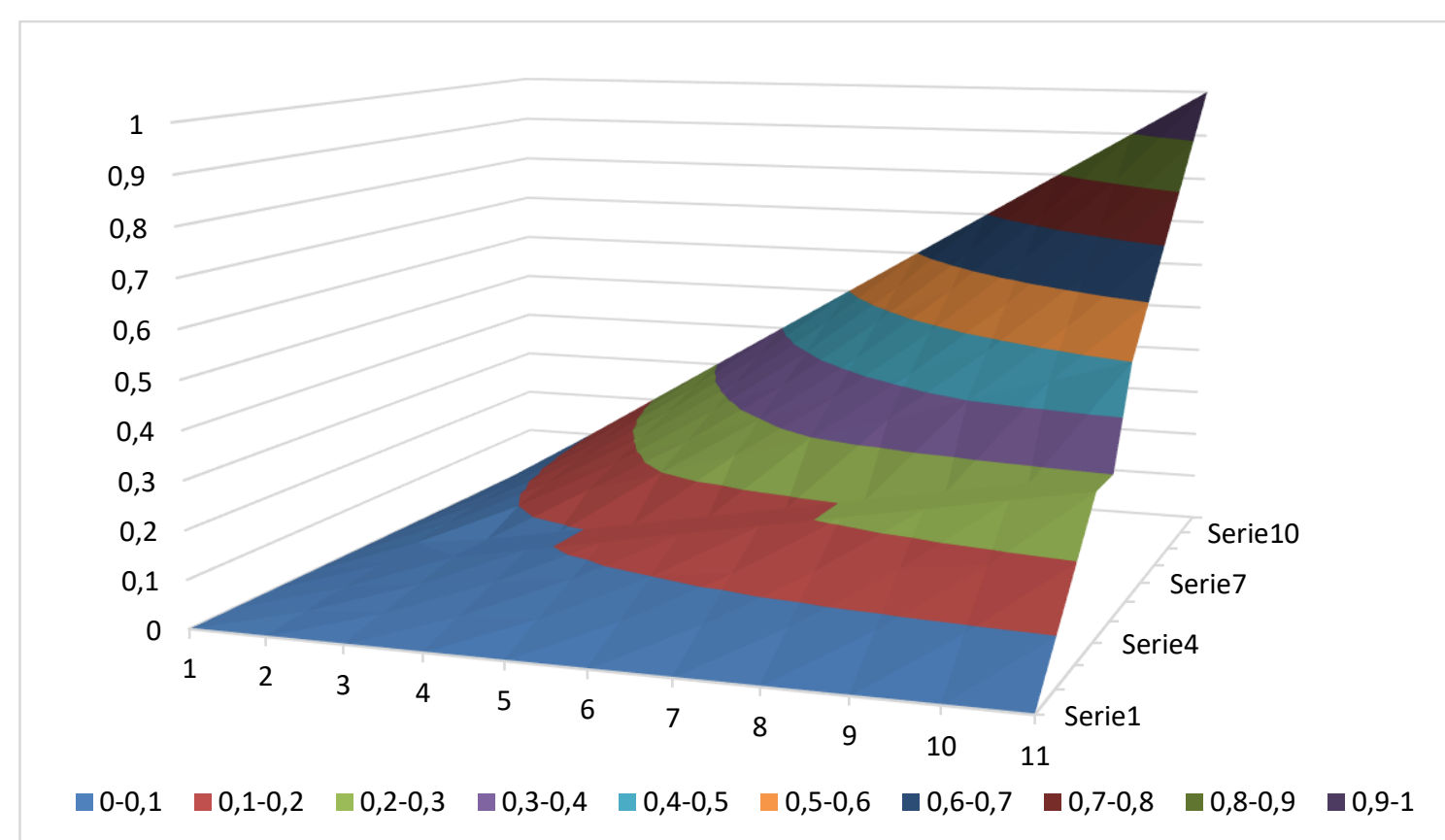

PICBE |

1213

Figure 2. Visual representation of a theoretical output of the qualitative and quantitative function

Source: Author own creation.

Figure 2 depicts the likely outcome of the application of the quantitative and qualitative factors in a theoretical model (therefore the perfect slope and equal weights in the layers). We have considered that the model scores both a quantitative and qualitative criteria for each institution on a scale from 0 (not meeting at all the respective criteria) to 1 (meeting in full the criteria) in 0.1 increments. The combination in the model is linear. Therefore, the combination of all qualitative and quantitative criteria would behave like the graphic in Figure 2. It is for the authority to calibrate the model and decide, for example if the top 5 bands are all in for public interest and the bottom 5 are not (therefore the discrimination is made through calibration set out in advance and therefore little use for an expert judgement) or if the method would indicate that only the 1 top and 1 bottom band meet the desired criteria and the decision for the other 8 middle bands will have to be made with expert judgement.

As seen above, in general, the existing qualitative and quantitative methods, in practice, are likely to not yield a sufficiently high discriminatory power to provide a definitive conclusionyes/no - to determine the extent to which an objective is met.

The introduction of the expert judgement should resolve this shortcoming. This is visually represented in Figure 3: the layer at the bottom are banks for which the objective is not met while the layer at the top are banks for which the objective is met. In case the calibration is not precise on all potential outputs or if the model is not robust for certain situations, the expert judgement is used to decide for outputs in the middle layers if they should be in the public interest category or not. The basis in Figure 3 is represented on one axis by the qualitative methodology and by the qualitative methodology by the other axis. 


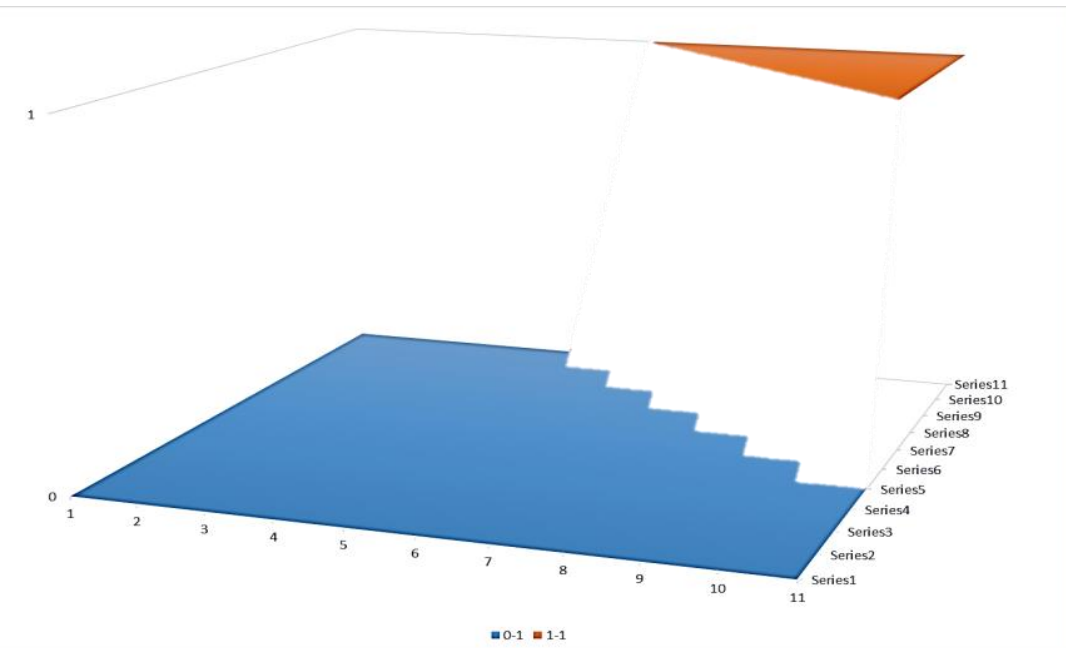

Figure 3. Employment of expert judgement to provide high discriminatory power in the assessment

Source: Author own creation.

Let's suppose that the financial system can be described by a structure of standardised indicators and measures for each specific component of the public interest. The outcome of applying the qualitative and quantitative methodologies could be visually represented via a system of axes: one axis for the qualitative (transposed in a quantifiable system) outcome and one axis for the quantitative outcome. Figure 4 proposes a visual representation of this approach. Each bubble represents an institution in the system (bubble size represents the relative size of each institution). Institutions are then plotted in categories over a system of axes. The axes represents calibrations made by the resolution authority in respect to the institutions' situation in relation to the public interest.

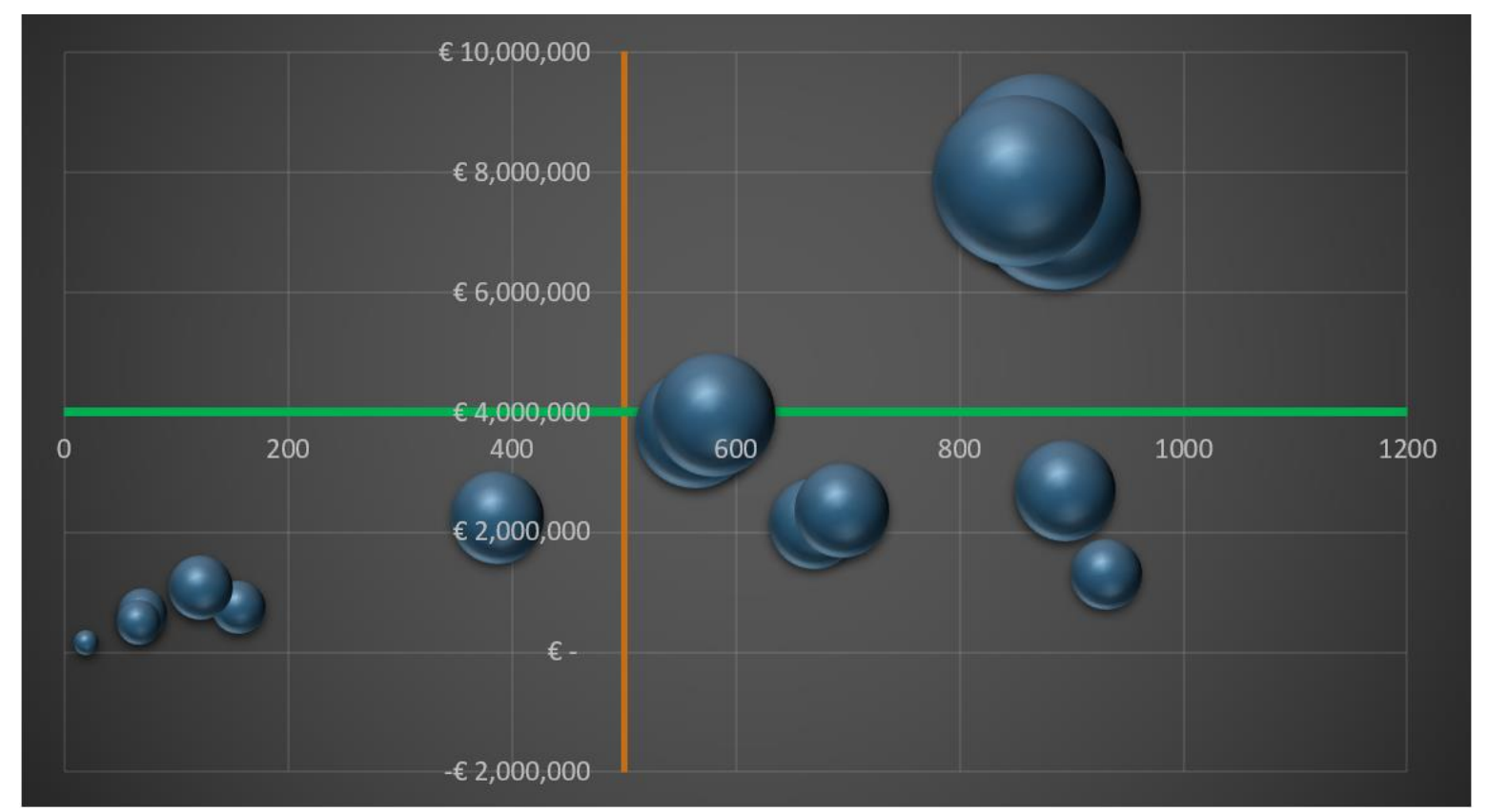

Figure 4. Proposal for a graphical output of PIA for quantitative and qualitative methodologies

Source: Author own creation. 
The visual simulation in Figure 5, has the following interpretation:

i.the horizontal line is the qualitative metric; everything to the right (above 500 points in our mock example) is considered relevant for PI;

ii.the vertical line is the reference for the quantitative metric and everything above 4 mio EUR ${ }^{1}$ is considered relevant for PI;

iii.As an outcome, institutions in the right upper quadrant are positive for PIA; institutions in the left lower quadrant are negative for PIA;

iv.Institutions that cross/overlap the lines and/or are in the lower right quadrant can be subject to an expert judgement to move them to one of the other quadrants or could be considered important only in case of systemic failures.

On calibrating the thresholds (the axes), expert judgement is employed to reflect a resolution authority's view of the economic background and any other specificities of the country. A transparent and pre-determined calibration (as is the case of O-SII and simplified obligations) can support predictable outcomes and coordination of measures. Stating clearly at times of "business as usual" where the thresholds are could potentially reduce pressure on authorities/governments to decide for public intervention in case of failure events, driven by fear of unpredictable market reactions.

The second point in the calibration system regards the "systemic vs idiosyncratic" approach. The resolution plan can outline the measures to be taken in case of bank failure, regardless of the cause of the failure. The question is: what should be the plan for institutions in the right lower quadrant: liquidation or resolution? The answer should include reflections on the following points:

i. The systemic scenario (at the planning stage) could be very wide, potentially triggering many institutions to be for public interest (large surface of the lower right quadrant).

ii. The size of the lower right quadrant could have immediate costly consequences for the institutions in this perimeter: they would be required to hold MREL. However, under individual failure events they would be left for liquidation, therefore the cost of MREL in isolated failures would not have been justified. If the MREL is balanced with a probability of default under systemic crisis (therefore reduced) its amount would not be sufficient should a resolution action be required due to the systemic failure.

Further employment of the model could facilitate the task of the resolution authority to decide on the use of the appropriate mix of resolution tools and powers. As the BRRD grants resolution authorities a number of resolution tools, the question is what is the most efficient combination of these tools to be used. In modelling this next step, we will introduce a new variable: the cost of the resolution action. Let us imagine a situation of a failing bank. The resolution authority identifies unequivocally that liquidation cannot meet the objectives - Figure 5 .

\footnotetext{
${ }^{1}$ Not necessarily balance sheet size; could be a composed calculation taking into account own funds, MREL, NPL, certain types of exposure etc.
}

DOI: 10.2478/picbe-2021-0112,pp. 1208-1218, ISSN 2558-9652 |

Proceedings of the $15^{\text {th }}$ International Conference on Business Excellence 2021 


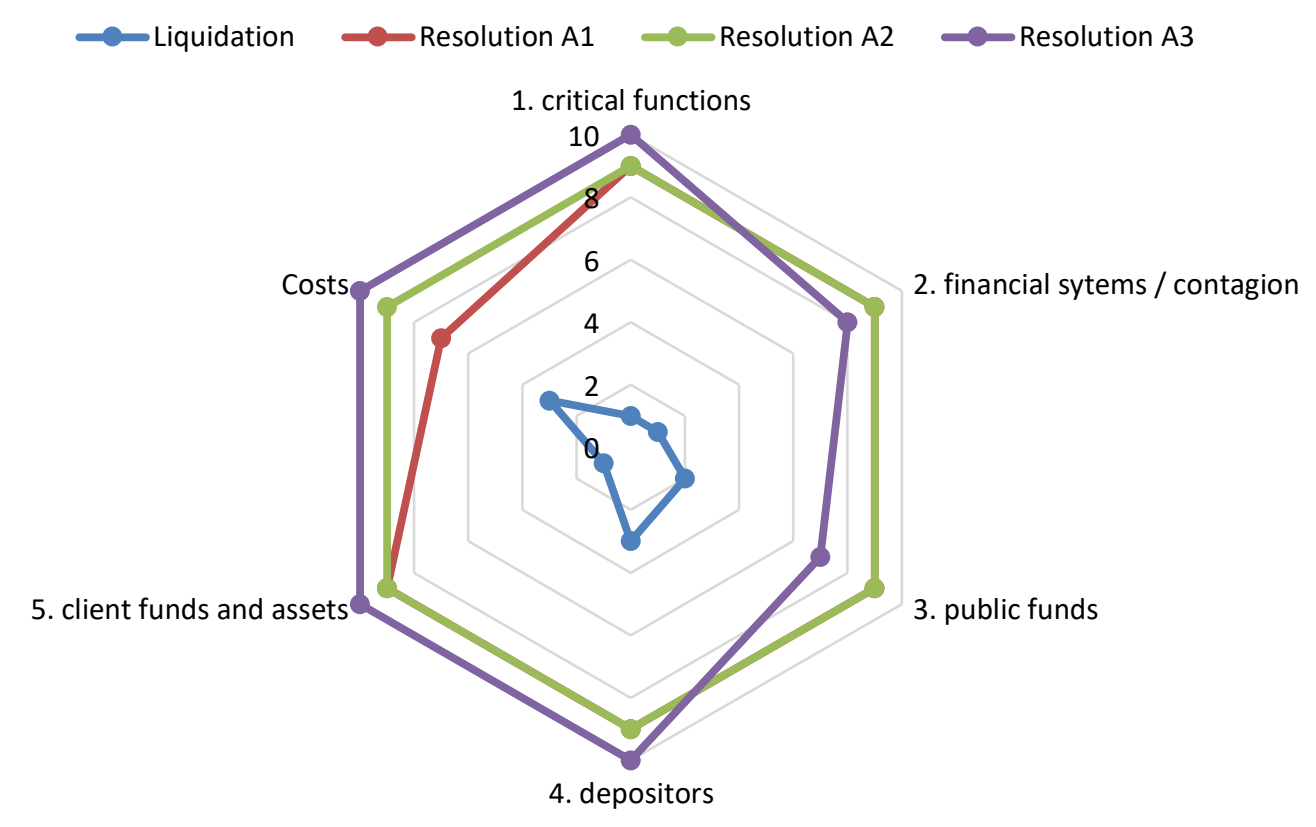

PICBE |

Figure 5. liquidation versus several combinations of resolution tools in resolution action

In the example from Figure 5, the situation is clear from one perspective: any of the possible combinations of tools for a resolution action is better compared to an insolvency process. Of course, the model oversimplifies real life - it makes it easy and evident on how each objective is achieved in a comparable manner.

In our theoretical example, resolution action A1 is similar with Resolution A2 except for the cost. A2 is more effective. However, the question is how do we compare A2 with A3? A3 is better than A2 for 3 objectives, including costs, than A2 but is worse for different two other objectives. By introducing this addition variable - the cost - the model can account for a higher degree of discrimination in choosing over the exact combination of resolution tools to be used.

\section{Results and discussions}

The public interest concept introduced by the legal framework. As long as the legal framework does not reference indicators (i.e. exact way of determining the underlying objectives) and relevance thresholds, the determination of the outcome remains an expert judgement call. In practice, this means that authorities tasked with the determination needs to ponder the various elements and make a call.

The concept of public interest for resolution purposes is new, therefore it is unlikely to be able to determine and calibrate a model based on historical data. Even in this case, the back testing would be biased against the indicators that would be taken into account in the measurement of various factors.

Regardless, the proposed model can serve the purpose of a structured analysis and offers the benefit of standardising to a certain point some elements. Using a standardised set of elements to monitor behaviours over time could create baselines and reveal evolution trends.

The modelling in this paper should be given a disclaimer: not only did we simplify the overview of resolution action decision process, but we assumed it is easy to assess all the potential 
outcomes. In a real scenario, there could be a very fine and subjective lines between potential insolvency outcomes compared to resolution outcomes.

In all these cases, the resolution authority will need to make a decision based on assumptions. In the end, the resolution action will be called into question based on the actual outcome comparing it to a structure of different theoretical outcomes (the paths that were not chosen and therefore their outcomes cannot be observed but only estimated).

Setting a standard for the banks' databases (as opposed for only standardised reporting) will allow for fast audits and valuations of the various portfolios and financial positions. Further, in case of a failed bank, interested buyers will be able to bid for different portfolios (be it customer or geographically shaped, for example). Having more buyers interested in smaller pieces of a failed bank (as opposed to having a single large buyer to purchase the whole) should conduct to a better overall price. Due to limitations in dismantling a failed bank in its constituent portfolios requires, in practice, a large enough buyer. Having a single buyer for a failed entity not only limits the pool of potential buyers (only entities larger than the failed one would qualify), but also decreases the market competition, creating a new too big to fail institution (n-1 institutions in the market, with the acquiring institution theoretically being double in size to the failed bank).

Having a multitude of buyers, each with adequate solvency and liquidity to purchase a small portfolio of the failing bank, would allow for an increase in market competition ( $n+x$ players) while also decreasing the number of too big to fail banks. Not least, having multiple bids over the failed banks portfolios should conduct to the best revenue for the deal.

\section{Conclusion}

The model proposed in this paper is a first attempt to mathematically model the public interest assessment under the European resolution framework.

More considerations can be brought to improve the model in different dimensions: identifying concrete quantitative and quantitative process for each of the five resolution objectives and determining the variables that should be used in these evaluation process.

Nevertheless, the model should be seen as a tool to provide a structured overview of the process that should further help assess the various component parts and identify ways to provide work to increase efficiency in practice. As mentioned in the introductory parts, no model can be perfect, but some can be useful.

The model here proposed should help foster discussion in a unified language that should conduct to practical advancements in the matter.

\section{References}

Alexander, E. R. (2002). The Public Interest in Planning: From Legitimation to Substantive Plan Evaluation, Planning Theory, 226-249.

Box, G. E. (1979). Robustness in the strategy of scientific model building, Robustness in Statitics, 201-237, North Carolina, Academic Press.

DeYoung, R., Kowalik, M., \& Reidhill, J. (2013). A theory of failed bank resolution: Technological change and political economics, Journal of Financial Stability, 612-627.

European Commission (2014). Bank recovery and resolution, Retrieved from European Commission, https://ec.europa.eu/info/business-economy-euro/banking-and-finance/finan cial-supervision-and-risk-management/managing-risks-banks-and-financial-institutions/ bank-recovery-and-resolution_en. 
European Parliament and Council (2014, May 15). Directive 2014/59/Eu of the European Parliament and of the Council of 15 May 2014 establishing a framework for the recovery and resolution of credit institutions and investment firms, Bruxelles, European Union.

Mitrache, G.R. (2018). Analyzing, Assessing and Determining Critical Functions and Relevant Credit Institutions within the Banking Resolution Regulatory Frame - Proposal for a Practical Approach, Journal of Knowledge Management, Economics and Information Technolog, 1-20.

Mitrache, G.R. (2018). A game of bank resolution, Theoretical and Applied Economics, 209-217. Neumaier, A. (2004). Mathematical Model Building, Applied Optimization.

Ouliaris, S. (2011, June). What Are Economic Models?, Finance \& Development, 46-47.

Rogers, K. (2011, April 11). Scientific modelling, Retrieved from Britannica, https://www.britan nica.com/science/scientific-modeling. 